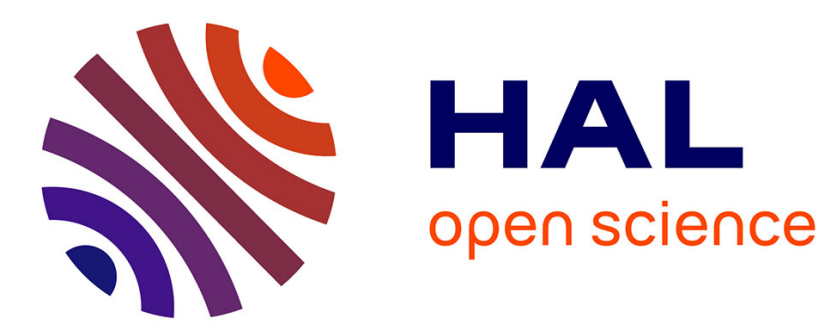

\title{
Personal data protection: are the GDPR objectives achieved amongst information and communication students?
}

Emmanuelle Chevry Pébayle, Hélène Hoblingre

\section{- To cite this version:}

Emmanuelle Chevry Pébayle, Hélène Hoblingre. Personal data protection: are the GDPR objectives achieved amongst information and communication students?. ELPUB 2020 24rd edition of the International Conference on Electronic Publishing, Apr 2020, Doha, Qatar. 10.4000/proceedings.elpub.2020.15 . hal-02544320

\section{HAL Id: hal-02544320 \\ https://hal.science/hal-02544320}

Submitted on 16 Apr 2020

HAL is a multi-disciplinary open access archive for the deposit and dissemination of scientific research documents, whether they are published or not. The documents may come from teaching and research institutions in France or abroad, or from public or private research centers.
L'archive ouverte pluridisciplinaire HAL, est destinée au dépôt et à la diffusion de documents scientifiques de niveau recherche, publiés ou non, émanant des établissements d'enseignement et de recherche français ou étrangers, des laboratoires publics ou privés. 


\title{
Personal data protection: are the GDPR objectives achieved amongst information and communication students?
}

\author{
Emmanuelle Chevry Pébayle and Hélène Hoblingre
}

\section{Background}

1 The European Union is showing growing concerns for transparency when using and holding digital data, especially as digital traces "are profitable 'raw materials'" (Boullier, 2015). A great example of this phenomenon, the Facebook and Cambridge Analytica scandal brought companies selling their users' personal data to light, without them questioning the legal aspect of the sale nor the use of data (Manokha, 2018). A great example of this phenomenon, the Facebook and Cambridge Analytica scandal brought to light the fact that companies were selling their users' personal data, without questioning them about the legal aspect of the sale or the use of data (Manokha, 2018).

Since 2018, the General Data Protection Regulation (GDPR) demands transparency from companies and imposes new restrictions on data transfers (Botchorishvili, 2017). Through the right to data portability (Zolynski \& Roy, 2017), the regulation advocates for the right that holds individuals to protect their personal data (Clément-Fontaine, 2017). Indeed, the GDPR allows individuals to : (1) "know the reason for personal data collection ; (2) understand the use of their data ; (3) control their data, facilitating the exercise of their rights" [1]. "Knowing", "understanding" and "controlling" one's data are all part of a learning process enabling individuals to develop a new relationship with their personal details. Data transparency opens up a new educational space for the user, including analysing, understanding and controlling their personal digital data. 


\section{Questioning}

3 According to Susan. B Barnes (2006), Internet users have concerns with personal data collection and respect, while enabling free access to their data. "In practice, the benefits outweigh the fears" (Pras, 2012). This inconsistency between the individuals' wishes and their actions is known as the "privacy paradox". According to Bernard Pras, this phenomenon primarily affects "young people" (2012). Thus, the achievement of the GDPR objectives may be up against the privacy paradox. In addition, one may ask if this phenomenon exists amongst young people studying information and communication sciences. Overall, it is likely that they relate to the GDPR, while they tend not to master nor understand the use of their personal data.

Indeed, although new generations are "digital natives", one should not forget (Le Deuff, 2010) that young people need to be digitally trained. Being digitally literate leads to digital acculturation. A recently published book written by Dominique Cardon (2019a) and entitled Culture numérique provides a summary of his teaching content. The sociologist highlights that the digital culture is fed by knowledge and questioning, particularly in relation to the future of digital data, behind which the spectrum of digital surveillance is taking shape (Cardon, 2019b).

Several questions can be raised. Do information and communication students believe in the GDPR? How do they analyse personal data? Is the students' analysis of their personal data a new monitoring space, along with e-reputation monitoring? What are the skills needed to control data? Are information and communication students trained enough to analyse their personal data? Our hypothesis is that the students' training does not yet enable them to meet the GDPR objectives.

Moreover, from a behavioural perspective (Mariné \& Escribe, 2012), particularly in John Broadus Watson's work (1928), it would be interesting to analyse the IUT students' practices to find out whether they could forget about data protection when conditioned by the interface and having acquired reflex actions.

7 This research addresses the GDPR objectives from a multidisciplinary perspective, involving both information and communication sciences and educational sciences. In addition, no research so far has been conducted to determine whether the privacy paradox extends to information and communication students.

\section{Methodology}

8 To find answers to our questions, we gave information and communication students a questionnaire. IUT students were best placed to get training in analysing and using their personal data. The national educational programme in place for DUT digital information organisations states that the diploma holder "must be able to master, adapt and develop digital communication tools and devices". To do so, one shall be capable of identifying "information issues" and having knowledge of "regulatory and legal frameworks" (p. 6). These two expectations imply agreeing with the GDPR objectives.

The aim of the questionnaire was (1) to find out about students' current practices in terms of personal data; (2) check that the GDPR objectives were achieved by the students; and (3) ensure they agreed with the goals. In addition, the questionnaire and the test provided an understanding of the skills needed by IUT students to achieve the 
GDPR objectives. Students were asked about their perception of these goals as key educational issue.

\section{Outcomes}

1070 students provided answers to 32 questions. Among the 70 students, 52 are studying Information and Communication and 16 are studying Education Sciences. Most of the respondents ranged from 18 to 20 years old. Fifty of them were women and a large proportion of the participants included $1^{\text {st }}$ and $2^{\text {nd }}$ year Information and Communication students.

11 Overall, students used Instagram the most, followed by YouTube, Facebook and Snapchat. The Google search engine was used on a daily basis.

12 More than two-thirds of the respondents gave a correct definition of the GDPR. They also believed that personal data protection was a key matter. Information and Communication students (66\%) are more numerous to know what RGPD is than Education Sciences students. However, this percentage seems low if we consider the content of Information and Communication students' training program. A minority of students knew that they could export their personal data collected by Google, although they would not benefit from downloading them. Indeed, their main motivation was to find out what Google knew about them.

13 As can be seen in Figure 1 below, more than two-thirds of the respondents considered that individuals should know the reason behind data collection as well as its use. Information and Communication students are more numerous to be convinced than Education Sciences students that training individuals is necessary. Indeed, those studying information and communication are more prone, thanks to their curriculum, to understand the issues of personal data protection. Therefore, the students who a priori know the most are more aware of the need to improve their knowledge through training. This phenomenon is somewhat reminiscent of the Matthew effect according to which "training goes to training" (Grazier, 2015) : therefore, the best-trained are the ones who benefit from training in the first place. 
Figure 1: Question 22. Is it necessary to train and educate individuals to master their digital data ? Comparison of student's representations by subject area

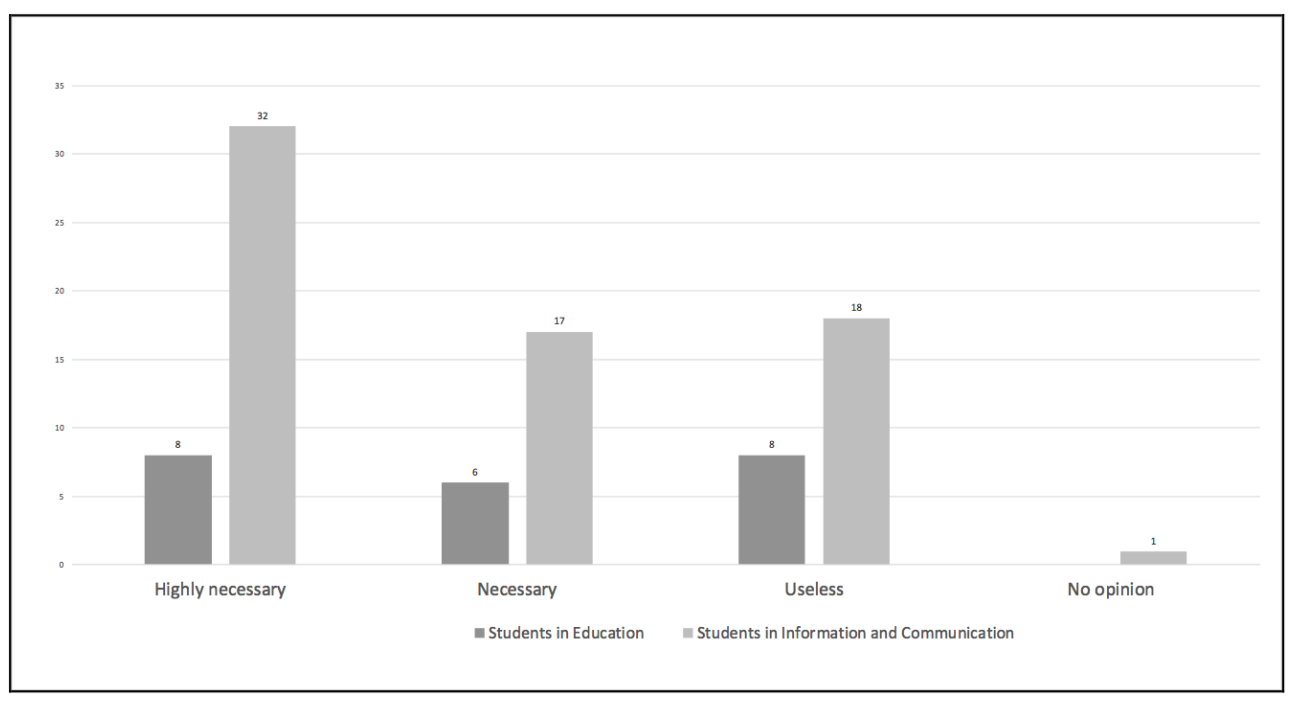

(The image copyright belongs to the authors)

14 Students also mentioned that the disclosure, theft and resale of their data were important threats to uncareful users. Many other risks were noted such as identity theft, use of data by unscrupulous governments, haggling, piracy, and so on, showing that students had a fairly comprehensive view of the risks when lacking data protection. However, students were very divided on data monetization: 15 believed it was legitimate while 23 had no opinion. Moreover, Information and Communication students are much more likely to think that monetizing data is legitimate (13 over 54) compared to 1 over 16 Education Science students.

For the vast majority of respondents, data protection is an important or even a very important issue, but data protection is not a democratic issue for them, up to a quarter of respondents. They are more sensitive to the marketing ( 40 over 54 ) and sale of their data, rather than to the risks that this exploitation could represent for democracy as the figure 2 below demonstrates. On this point, the responses are different between the two panels. Information and Communication students are more likely to have no opinion on the question. On the other hand, it is among the students in education sciences that there is the greatest gap between those considering that there is a risk for democracy and for individual freedom and those denying the risk. It can be surmised here that it is due to the fact that students in Information and Communication are better trained in the field of democratic and individual freedom. 
Figure 2: Question 20. What leads you to consider the protection of personal digital data as a (very) important issue? Comparison of students view by discipline area

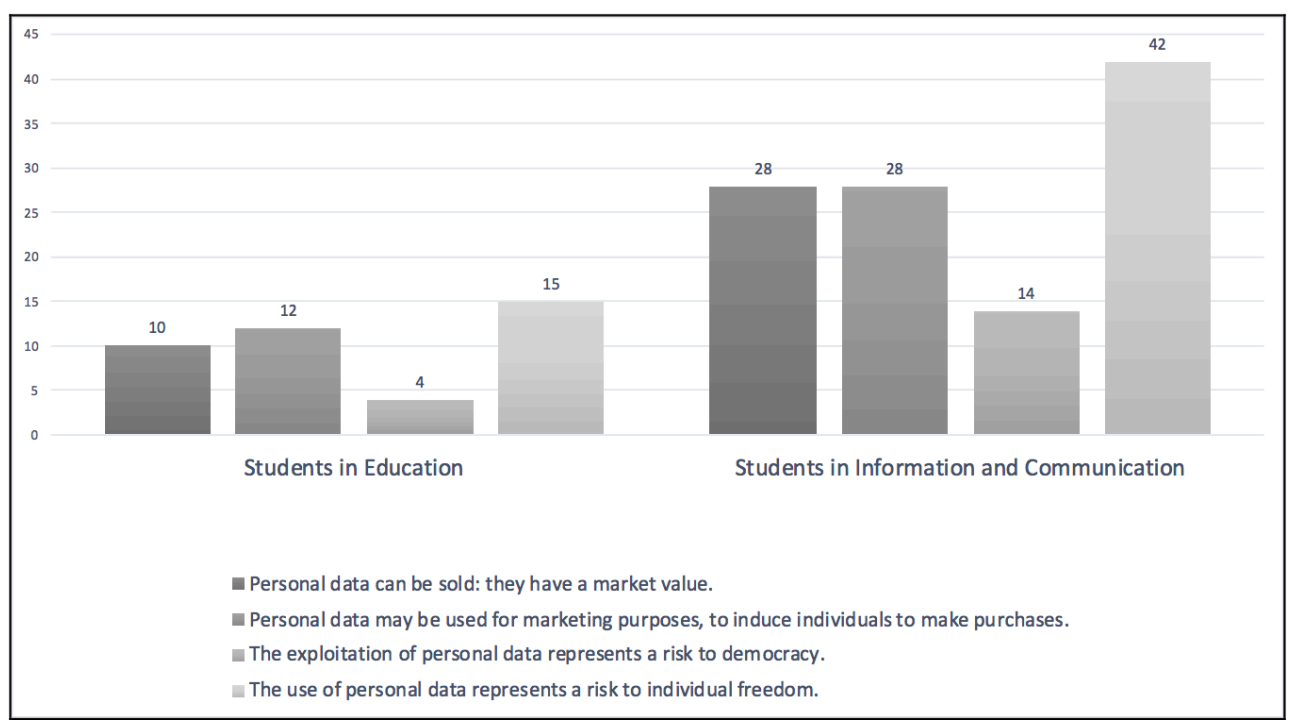

(The image copyright belongs to the authors)

Although a majority of students highlighted that digital privacy was a right for individuals, nearly a quarter of them was willing to sacrifice it if needed in order to use applications "for free". Another quarter was undecided on this issue. Although, students did not agree on their data to be traded without prior knowledge, they were open to data commodification, provided that the user was the seller. However, this voluntary commodification would impact on individual freedom, for which students had initially raised concerns. In practice, the situation differed. When students were confronted to the following message: "By continuing your navigation, you accept the deposit and use of cookies for site operation, visit statistics and sharing for social networks, the majority clicked on Accept without reading the terms and conditions. Our panellists were part of the privacy paradox, implying that palpable and immediate benefits outweighed potential and hidden risks.

17 A political reading of these results would suggest that students aligned with a liberal approach to personal data. Many respondents were concerned that the use of personal data may affect their individual freedom. Fewer considered the risks it would have on democracy. All respondents wish to control and protect their data as an individual responsibility, but are they willing to sell personal information to the highest bidder?

Respondents are often willing to sacrifice their privacy for services. Would students feel they have no choice? Is it a matter of time? Do they feel like they're being held hostages, at a time when everything has to move fast? We have become so used to having access to this service that we are no longer prepared to give it up: we are already conditioned. It is moreover on this conditioning that GAFAM plays to monetize services: they get us used to these services for free and then they monetize them. The answers highlight the difficulty to answer this question, and perhaps the way in which individuals are tugged. 


\section{Research perspectives}

19 The results may mean that students are generally caught up in automatic reflexes. These reflexes would prevent them from worrying about knowing, understanding and controlling their data. This phenomenon has already been called "consent fatigue" (Pascuzzi et al., 2013, p. 176). Indeed, consent forms stop users when they arrive on a website, and they "can cover the page and ruin the user experience " (MEF's Consumer Trust Working Group, 2018, p. 12). Thus, they affect the ergonomics of the internet navigation and they can be perceived as an annoyance. From learning theory, we can even consider that " consent forms " has another effect: interrupt "schema". The notion of «schema » has been created by Emmanuel Kant, it was further developed by Piaget and then by Vergnaud in the field of Professional didactic (Pastré et al., 2006) . From Vergnaud's definition, a schema is " an invariant activity organization for a defined class of situations" (Vergnaud, 2001, p. 110). Thus, the navigation of a user is built on different schemas. Considering that consent forms interrupt a certain type of activity (looking for information) by another required activity (to field a form about protection of data), we can assume that consent forms interrupt schema. Moreover, one might wonder whether such forms generate mental workload (made of a feeling of guiltiness and responsibility) as well as digital labor (Cardon \& Casilli, 2015). Does the portability of the conditions of respect for personal data would be a solution to avoid this consent fatigue?

The results of our exploratory research lead us here to propose an interview guide for semi-structured interviews to be conducted with Information Communication students.

These interviews should, firstly, allow us to understand why the failure to protect one's personal data constitutes a greater risk for individual freedom than for democracy. It would be a question of knowing how students conceive democracy and if they do not take certain freedoms for granted (e.g. freedom of clothing, sexual orientation, freedom to demonstrate in the street, etc.). Secondly, it would make it possible to understand why CIS students think (13 out of 54) that monetizing data is legitimate.

We have therefore formulated the following hypothesis, which may help to explain in part why these students have this point of view.... Here is our hypothesis: monetizing data seems legitimate to them because they take courses that deal precisely with the economic exploitation of digital personal data. These courses allow them to understand that behind the apparently free sharing of data on the Web, there is an economic model operating on the principle of data monetization. Infocom students, having a particular understanding of this economic functioning, therefore approach it perhaps in a more analytical or resigned manner than students in education sciences who are more prone to value judgments. 


\section{BIBLIOGRAPHY}

Barnes, Susan B. “A Privacy Paradox: Social Networking in the United States.” First Monday, vol. 11, no. 9, Sept. 2006. doi:10.5210/fm.v11i9.1394.

Botchorichvili, Nana. “Transferts de données personnelles hors de l'Union européenne - Quelles nouveautés avec le RGPD ?” LEGICOM, vol. 59, no. 2, 2017, p. 39. doi:10.3917/legi.059.0039.

Boullier, Dominique. "Les sciences sociales face aux traces du big data: Société, opinion ou vibrations ?" Revue française de science politique, vol. 65, no. 5, 2015, p. 805. doi:10.3917/rfsp. 655.0805 .

Cardon, Dominique \& Casilli, Antonio. Qu'est-ce que le Digital Labor ?. Institut National de l'Audiovisuel, 2015.

Cardon, Dominique. Culture numérique. Presses de Sciences Po, 2019.

Gazier, Bernard. "IV. L'investissement dans les ressources humaines." Les Stratégies Des Ressources Humaines, by Bernard Gazier, La Découverte, 2010, pp. 61-79.

Le Deuff, Olivier. "La skholè face aux négligences : former les jeunes générations à l'attention." Communication \& langages, vol. 163, no. 1, NecPlus, 2010, pp. 47-61. doi:10.4074/ S033615001001104X

Manokha, Ivan. "Le scandale Cambridge Analytica contextualisé : le capital de plateforme, la surveillance et les données comme nouvelle « marchandise fictive »." Cultures \& Conflits, no. 109, July 2018, pp. 39-59. doi:10.4000/conflits.19779.

Mariné, Claudette, and Christian Escribe. "Naissance du behaviorisme. Tout est conditionnement." Histoire de la psychologie, Éditions Sciences Humaines, 2012, pp. 75-77. doi: 10.3917/sh.marmi.2012.01.0075

Pascuzzi, Giovanni, et al., editors. Comparative Issues in the Governance of Research Biobanks. Springer Berlin Heidelberg, 2013. doi:10.1007/978-3-642-33116-9.

Pastré, Pierre, et al. "La didactique professionnelle." Revue française de pédagogie, no. 154, Mar. 2006, pp. 145-98. doi:10.4000/rfp.157.

Pras, Bernard. "Entreprise et vie privée. Le « privacy paradox » et comment le dépasser ?" Revue française de gestion, vol. 224, no. 5, Lavoisier, 2012, pp. 87-94, www.cairn.info/revue-francaise-degestion-2012-5-page-87.htm.

Vergnaud, Gérard. "Piaget visité par la didactique." Intellectica. Revue de l'Association pour la Recherche Cognitive, vol. 33, no. 2, 2001, pp. 107-23. doi:10.3406/intel.2001.1635.

Watson, John Broadus. Psychological Care of Infant and Child. W W Norton \& Co, 1928.

Zolynski, Célia, and Marylou Le Roy. "La portabilité des données personnelles et non personnelles, ou comment penser une stratégie européenne de la donnée." LEGICOM, vol. 59, no. 2, 2017, p. 105-113. doi:10.3917/legi.059.0105.

\section{ABSTRACTS}

Since 2018, the General Data Protection Regulation (GDPR), European Union regulation, demands transparency from companies and imposes new restrictions on data transfers (Botchorishvili, 2017). 
The purpose of this article is to analyze the uses and representations of information and communication science students regarding the RGPD and to compare it with that of students in the education sciences. This article is in line with the research on the Privacy Paradox and brings new elements of explanation thanks to the confrontation between two populations of students. In this perspective, a questionnaire was sent out to information and communication students and education sciences students. 70 students provided answers to 32 questions.

More than two-thirds of the respondents gave a correct definition of the GDPR. They also believed that personal data protection was a key matter. So much considered that individuals should know the reason behind data collection as well as its use. Information and Communication students are more numerous to be convinced than Education Sciences students that training individuals is necessary. Indeed, those studying information and communication are more prone, thanks to their curriculum, to understand the issues of personal data protection. Therefore, the students who a priori know the most are more aware of the need to improve their knowledge through training. In general students had a fairly comprehensive view of the risks when lacking data protection. However, students were very divided on data monetization : 15 believed it was legitimate while 23 had no opinion. Moreover, Information and Communication students are much more likely to think that monetizing data is legitimate (13 over 54 ) compared to 1 over 16 Education Science students.

\section{INDEX}

Keywords: privacy paradox, big data, personal data, digital education, digital literacy

\section{AUTHORS}

\section{EMMANUELLE CHEVRY PÉBAYLE}

University of Strasbourg

chevry@unistra.fr

(corresponding author)

\section{HÉLÈNE HOBLINGRE}

University of Strasbourg 